\title{
APLIKASI SISTEM ABSENSI GURU UNTUK DAPAT MENGUKUR PENINGKATAN KINERJA GURU PADA SMA NEGERI 3 KABUPATEN TANGERANG
}

\author{
Ruli Supriati $^{1}$, Nina Carolina ${ }^{2}$ \\ 1) Dosen Program Studi Sistem Informasi, ${ }^{2)}$ Mahasiswa Program Studi \\ Sistem Informasi. \\ ${ }^{1,2)}$ Fakultas Sains dan Teknologi Universitas Raharja, \\ Jl. Jend. Sudirman No. 40, Tangerang, Banten. \\ E-mail: ruli@raharja.info 1), nina.karolina@raharja.info ${ }^{2)}$
}

\begin{abstract}
Kebutuhan dalam pengolahan data yang cepat dan akurat dibutuhkan oleh setiap organisasi dan instansi swasta. SMA Negeri 3 Kabupaten Tangerang adalah salah satu instansi yang memerlukan sebuah sistem yang cepat dalam pengolahan data rekapitulasi absensi guru sehingga dapat menghasilkan grafik yang dapat digunakan untuk mengukur kinerja guru. Berdasarkan analisa sistem yang sedang berjalan diperoleh hasil bahwa sistem yang ada saat ini masih terdapat sejumlah kekurangan yaitu kurang adanya sistem absensi yang akurat, cepat dan tepat, karena system absensi yang ada pada SMA Negeri 3 Kabupaten Tangerang masih manual yaitu menggunakan tanda tangan. Untuk memperoleh data-data yang diperlukan selama penelitian penulis menggunakan beberap ametode, antara lain: wawancara, observasi dan studi pustaka. Tujuan dibuatnya sistem ini adalah agar Kepala sekolah dapat melakukan evaluasi terhadap kinerja guru berdasarkan absensi. Kedepannya akan dikembangkan dari sisi kinerja lainnya salah satunya adalah penilaian kinerja guru di dalam kelas. Apresiasi terhadap kedisiplinan absensi kehadiran guru juga dapat diberikan berupa reward untuk guru terajin dan yang tidak rajin dapat diberikan sanksi.
\end{abstract}

Kata kunci : Sistem Absensi, Mengukur kinerja guru

\section{PENDAHULUAN}

Komputer merupakan sistem informasi yang mendukung suatu organisasi untuk mengoptimalkan aktifitasnya dalam mencapai tujuan tertentu. Oleh karena itu instansi-instansi pemerintah maupun swasta memerlukan informasi yang diperlukan didapat dari pengaplikasian komputer.

Absensi memegang peranan yang sangat penting dalam setiap kegiatan yang dilakukan. Karena kita ketahui bersama bahwa komputer mampu memegang peranan terpenting sebagai alat bantu dalam pengolahan data serta dapat memecahkan masalah yang kecil sampai dengan masalah yang sangat kompleks sekalipun. Penggunaan 
komputer dapat dilengkapi dengan program aplikasi dapat memberikan hasil yang berkualitas. Dengan demikian penanganan sistem secara terkomputerisasi pada sekolah sangatlah tepat.

Untuk mengatasi permasalahan tersebut maka sekolah harus dapat menempatkan tenaga ahli yang terampil di bidang masing-masing serta mampu mengembangkan dan melaksanakan secara efektif dan efisien khususnya pada sistem absensi atau kehadiran.

Namun dalam hal ini seiring dengan berjalannya sistem ternyata masih terdapat kekurangan-kekurangan terhadap sistem yang sedang berjalan, keadaan sistem kehadiran guru yang ada di SMA Negeri 3 Kabupaten Tangerang masih menggunakan kertas dan buku sebagai media untuk melakukan proses kehadiran guru, sehingga pada saat ingin mengisi daftar hadir waktu yang digunakan tidak efisien dan dapat terjadi manipulasi data absensi antara guru yang satu dengan yang lain.

\section{Identifikasi Masalah}

1. Ingin mengetahui proses absensi guru yang sedang berjalan saat ini

2. Data absensi guru masih manual dengan menggunakan buku besar sehingga adanya hilang dokumen absensi

3. Mengalami kesulitan dalam proses pencarian data.

\section{Pembatasan Masalah}

Permasalahan yang akan dibahas dalam penelitian ini yaitu tentang pembuatan aplikasi sistem absensi guru guna mengukur peningkatan kinerja.

\section{Perumusan Masalah}

Berdasarkan latar belakang diatas, maka perumusan masalah penelitian ini adalah :

1. Bagaimanakah sistem absensi guru yang sedang berjalan saat ini pada SMA Negeri 3 Kabupaten Tangerang?

2. Bagaimanakah cara mengukur kinerja guru berdasarkan sistem absensi?

3. Apakah sistem absensi guru pada SMA Negeri 3 Kab. Tangerang yang berjalan saat ini sudah mampu menciptakan laporan dengan cepat dan akurat? 


\section{METODOLOGI PENELITIAN}

\section{Metode Observasi (Observation Research)}

Suatu metode pengumpulan data dengan cara mengamati secara langsung permasalahan di SMA Negeri 3 Kabupaten Tangerang Jalan Raya Curug, Km. 2 Curug Tangerang Pos. 15810, Kabupaten Tangerang, Provinsi Banten, pada saat observasi penulis melakukan pengumpulan data secara lengkap dan akan digunakan sebagai dasar dalam penelitian laporan kuliah kerja praktek.

\section{Metode Wawancara (Interview Research)}

Sejalan dengan sifat, tujuan dan ruang lingkup masalah penelitian atau sumber data yang berasal dari interview (wawancara) tanya jawab dilakukan dengan stakeholder.

\section{Metode Pustaka (Library Research)}

Digunakan untuk mendapatkan informasi dari beberapa literature yang ada. Dalam metode ini penulis berusaha melengkapi data-data yang diperoleh dengan membaca buku panduan penggunaan sistem kehadiran atau absensi guru. Buku dan data tersebut digunakan penulis untuk membantu penganalisaan dan perancangan yang dilakukan.

\section{Metode Analisis Data}

Pada penelitian ini, metode analisa dilakukan dengan langkah-langkah melakukan pengamatan dan analisa terhadap sistem yang berjalan saat ini, serta menentukan UML (Unified Modeling Language) yang meliputi use case diagram, activity diagram, sequence diagram.

\section{LITERATURE REVIEW}

Beberapa penelitian sebelumnya (literature review) telah dilakukan yang berkaitan dengan sistem sistem absen guru yang digunakan sebagai acuan, pertimbangan, dan perbandingan, serta untuk memperkuat hasil penelitian ini maka dilakukan identifikasi:

1. “Analisa sistem informasi Kehadiran Siswa pada SMA Negeri 6 Tangerang”. oleh Moch Nurkamarulloh (2009:2). Pada penelitian sebelumnya menjelaskan tentang masalah yamg dihadapi dari sistem yang ditelitinya di tempat tersebut. Karena di tempat tersebut untuk mengisi daftar hadir Siswa masih bersifat manual dan penyimpanan data terlalu lama dari sistem yang sekarang berjalan di tempat 
tersebut. Adapun kekurangan dalam penelitian ini belum terealisasi secara optimal karena program yang digunakan masih terlalu sulit dan belum terlalu di pahami oleh user maupun siswa.

2. “Analisa sistem informasi absensi karyawan pada Perguruan Tinggi Raharja”. oleh Puji Yurnaningsih(2010:4). Pada penelitian sebelumnya menjelaskan bagaimana sistem absensi karyawan di tempat tersebut . masalah yang dihadapinya dari sistem tersebut adalah, pada saat pendataan absen karyawan masih terlalu lama. Hasil penelitian merupakan data yang dipakai sebagai acuan untuk memperbaiki sistem yang sudah ada . adapun kekurangan pada penelitian ini sistem yang digunakan masih memerlukan spesifikasi komputer yang cukup rumayan, agar kinerja sistem tersebut berjalan secara optimal.

3. "Analisa sistem informasi absensi Pegawai pada Badan Pusat Statistik kota Tangerang”. oleh wati ismawati (2009:8). Pada penelitian penulis menjelaskan sistem yang sekarang sedang berjalan di tempat tersebut. Dari sistem tersebut dapat di simpulkan bahwa sistem yang sekarang sedang berjalan di sana masih bersifat manual, dimana saat Pegawai ingin absen, Pegawai hanya mengisi absensi dengan menggunakan tanda tangan. Kekurangan pada penelitian ini adalah sistem belum optimal dan belum dipakai karena perusahaan itu masih ingin menggunakan sistem yang lama, karena tingkat kesulitan sistem pada penelitian ini.

4. “Analisa Batam SMAN 4 Batam melalui penerapan Framework Code Igniter". Oleh Adi Pranadipa (2013). Absensi merupakan hal yang penting bagi suatu instansi ataupn dibidang pendidikan. Absensi dikatakan penting karena dapat melihat tingkat kedisiplinan satu siswa yang sering hadir maupun yang tidak hadir. Oleh karena itu dalam penerapannya haruslah diperhatikan dengan baik agar tidak menghambat kinerja seolah tersebut. Kehadiran program web aplikasi ini akan memberikan layanan sistem kehadiran dan ketidakhadiran siswa melalui rekapan data siswa yang bertujuan untuk membantu guru, guru piket dan Administrator dalam membuat rekapan data absen dalam bentuk laporan. Dalam membuat aplikasi web ini dibutuhkan software penunjang seperti PHP, Apache, CodeIgniter dan My SQL implementasinya dengan memaksimalkan kemampuan dalam mendesain dengan software pendukung yang digunakan. Dengan adanya tampilan rekapan absen yang bisa di lihat berdarkan persentasi kehadiran setiap kelas dan 
juga jumlah kehadirannya dan proses absensi di SMAN 4 Batam berjalan tepat waktu dan akurat untuk memproses informasi absensi yang dibutuhkan.

\section{PEMBAHASAN UML}

\section{Diagram Use Case Diagram}

Dalam Use Case Diagram administrator hanya melibatkan 1 aktor yaitu admin.

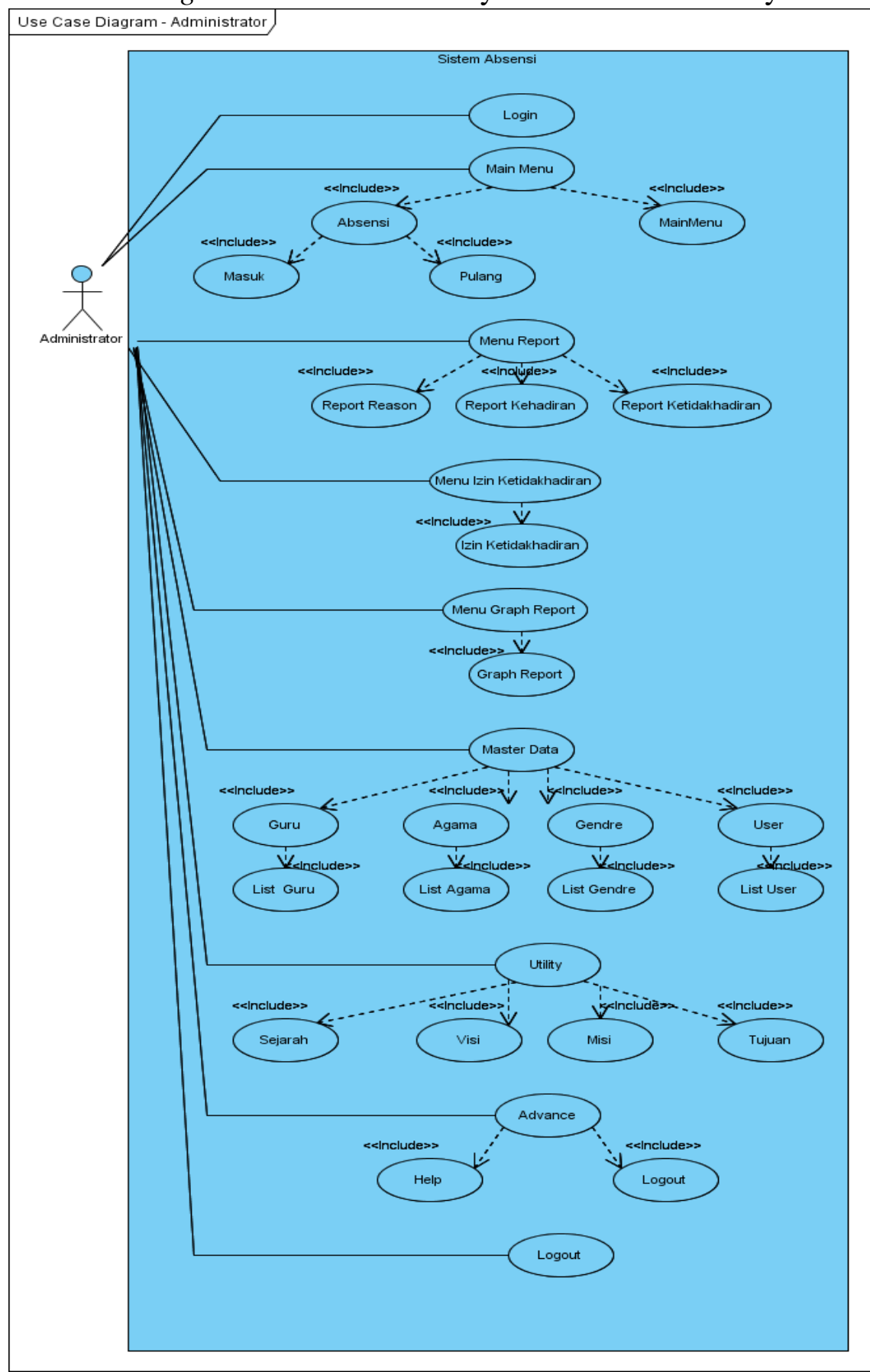

Gambar 1 Use Case Diagram administrator 
Tabel 1

Deskripsi Aktor dalam Usecase

\begin{tabular}{|l|c|l|}
\hline No & Aktor & \multicolumn{1}{c|}{ Deskripsi } \\
\hline 1 & Administrator & $\begin{array}{l}\text { Administrator dapat mengakses ke semua menu. Karena } \\
\text { bagian admin yang memegang peranan sistem absensi } \\
\text { guru. }\end{array}$ \\
\hline
\end{tabular}

Tabel 2

Deskripsi Usecase

\begin{tabular}{|l|l|l|}
\hline No & \multicolumn{1}{|c|}{ Usecase } & \multicolumn{1}{c|}{ Deskripsi } \\
\hline 1 & Login & Memvalidasi user yang masuk ke dalam system \\
\hline 2 & $\begin{array}{l}\text { Halaman } \\
\text { Utama }\end{array}$ & $\begin{array}{l}\text { Merupakan tampilan halaman ketika user masuk ke } \\
\text { dalam sistem aplikasi setelah berhasil login. Di dalam } \\
\text { tampilan ini terdapat beberapa menu untuk user }\end{array}$ \\
\hline 3 & $\begin{array}{l}\text { Master } \\
\text { Data }\end{array}$ & $\begin{array}{l}\text { Menu untuk mengimput data master yang dibutuhkan } \\
\text { Sekolah }\end{array}$ \\
\hline 4 & Menu absensi & $\begin{array}{l}\text { Menu yang di dalamnya terdapat fungsi untuk guru } \\
\text { dapat melakukan absensi }\end{array}$ \\
\hline 5 & Menu Report & Menu untuk menampilkan laporan absensi \\
\hline
\end{tabular}




\section{Usecase Diagram User}

Dalam Use Case Diagram administrator hanya melibatkan 1 aktor yaitu admin.

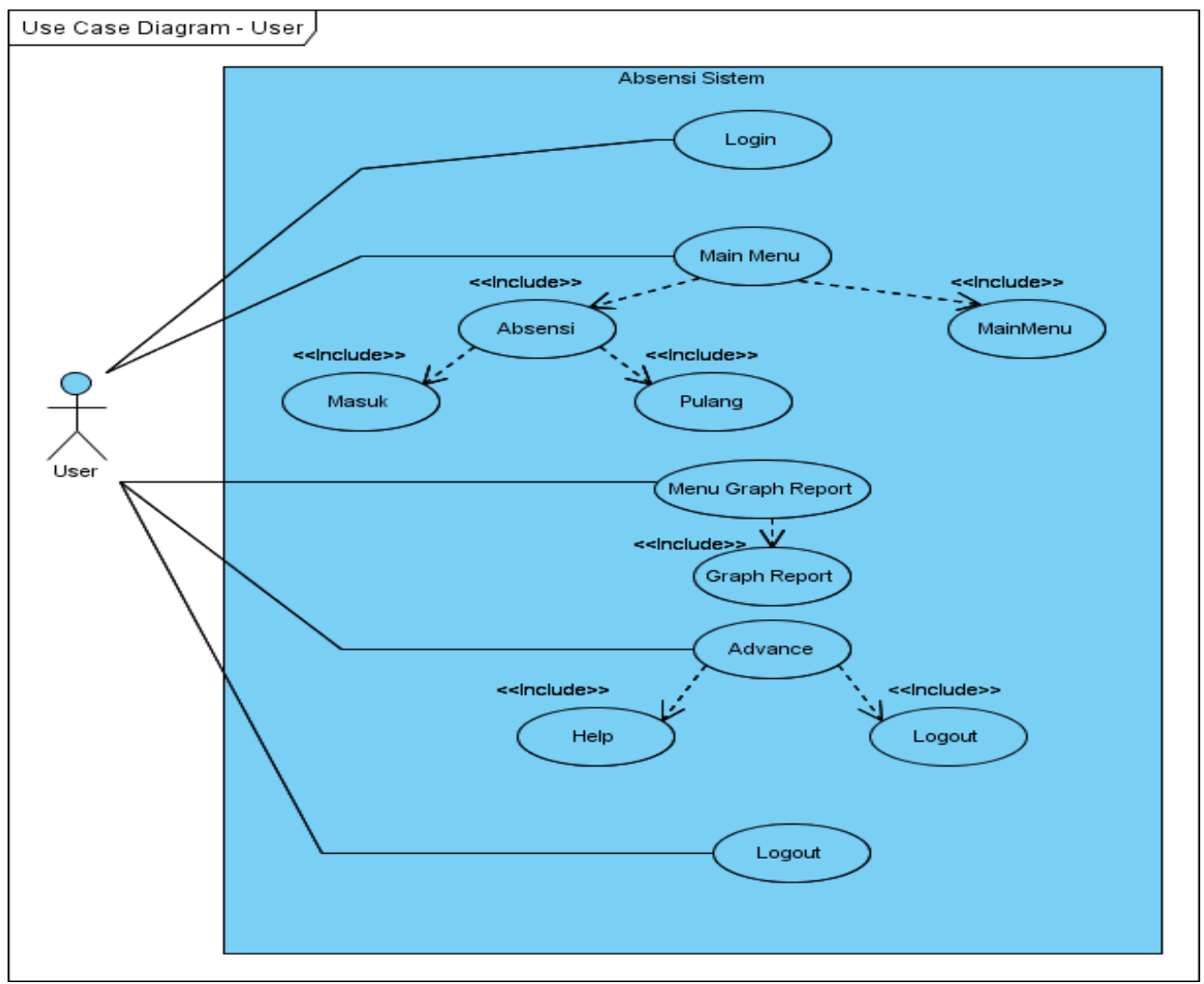

Gambar 2 Use Case Diagram User

Tabel 1

Deskripsi Aktor dalam Usecase

\begin{tabular}{|l|l|l|}
\hline No & \multicolumn{1}{|c|}{ Aktor } & \multicolumn{1}{c|}{ Deskripsi } \\
\hline 1 & User & $\begin{array}{l}\text { User adalah pengguna sebuah aplikasi yang dibuat } \\
\text { dan di implementasikan. Aktor user ini adalah Guru. } \\
\text { Karena sistem yang dibuat adalah sistem absensi guru. }\end{array}$ \\
\hline
\end{tabular}

Tabel 2

Deskripsi Usecase

\begin{tabular}{|l|l|l|}
\hline No & \multicolumn{1}{|c|}{ Usecase } & \multicolumn{1}{c|}{ Deskripsi } \\
\hline 1 & Login & Memvalidasi user yang masuk ke dalam system \\
\hline 2 & $\begin{array}{l}\text { Master } \\
\text { Data }\end{array}$ & $\begin{array}{l}\text { Menu untuk mengimput data master yang dibutuhkan } \\
\text { perusahaan }\end{array}$ \\
\hline 3 & Menu absensi & $\begin{array}{l}\text { Menu yang di dalamnya terdapat fungsi untuk } \\
\text { guru dapat melakukan absensi }\end{array}$ \\
\hline 4 & $\begin{array}{l}\text { Menu Graph } \\
\text { Report }\end{array}$ & $\begin{array}{l}\text { Menu untuk menampilkan laporan berupa grafik } \\
\text { sehingga terlihat siapa guru yang absensinya bagus dan } \\
\text { tidak bagus. }\end{array}$ \\
\hline
\end{tabular}




\section{Class Diagram}

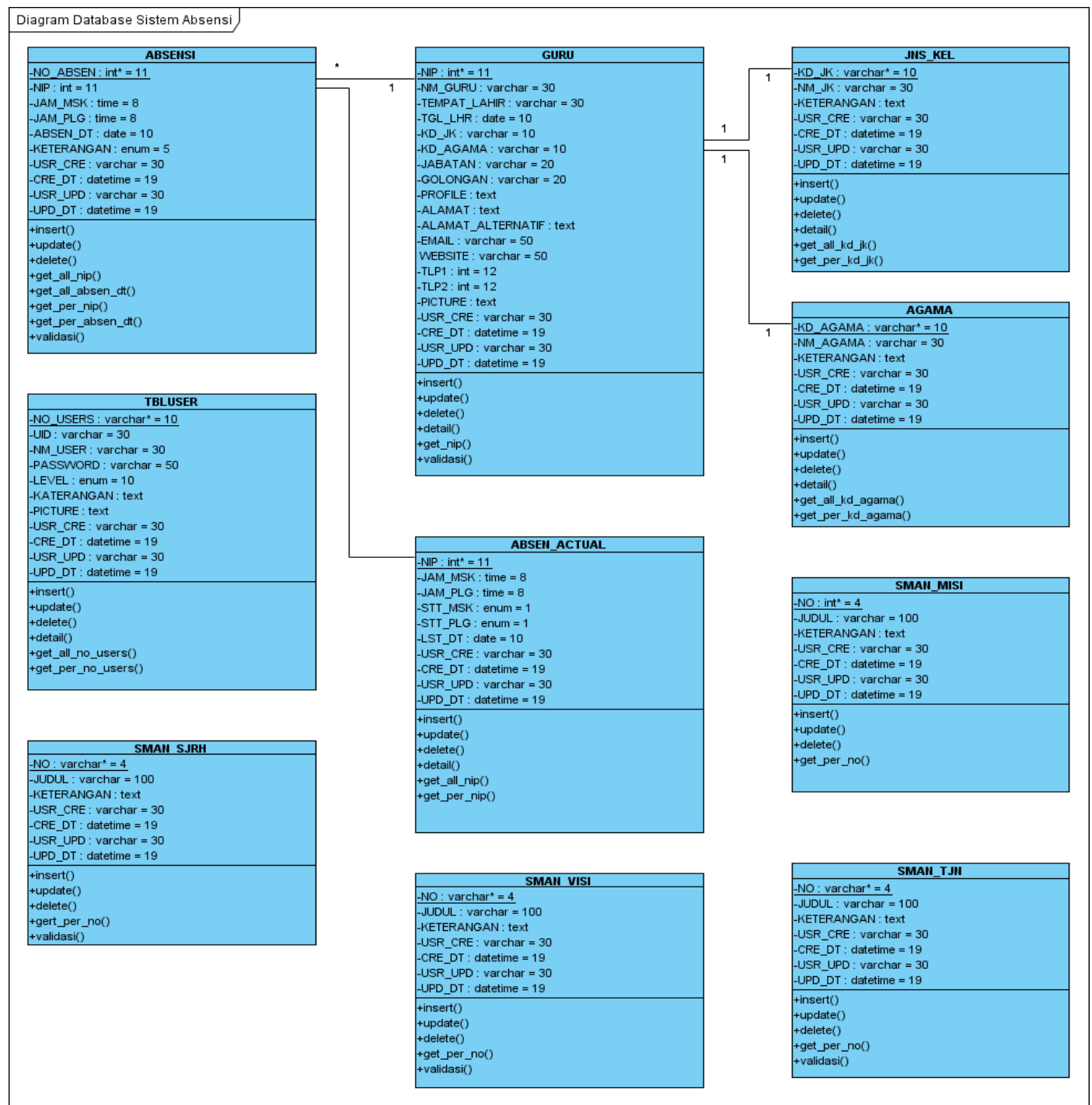

\section{Gambar 3 Class Diagram}

Tabel 1

Deskripsi Class Diagram

\begin{tabular}{|c|c|l|}
\hline No & Class Diagram & \multicolumn{1}{|c|}{ Deskripsi } \\
\hline 1 & 10 Table & $\begin{array}{l}\text { 10 Table: Table absensi, Table guru, Table Jns Kel, } \\
\text { Table agama, Table User, Table absensi actual, } \\
\text { Table SMAN Misi, Table SMAN Sjrh, Table } \\
\text { SMAN Visi, Table SMAN Misi. }\end{array}$ \\
\hline
\end{tabular}


Tampilan program

a. Tampilan Home berisikan sub menu yang dapat ditampilkan di dalam aplikasi program absensi guru

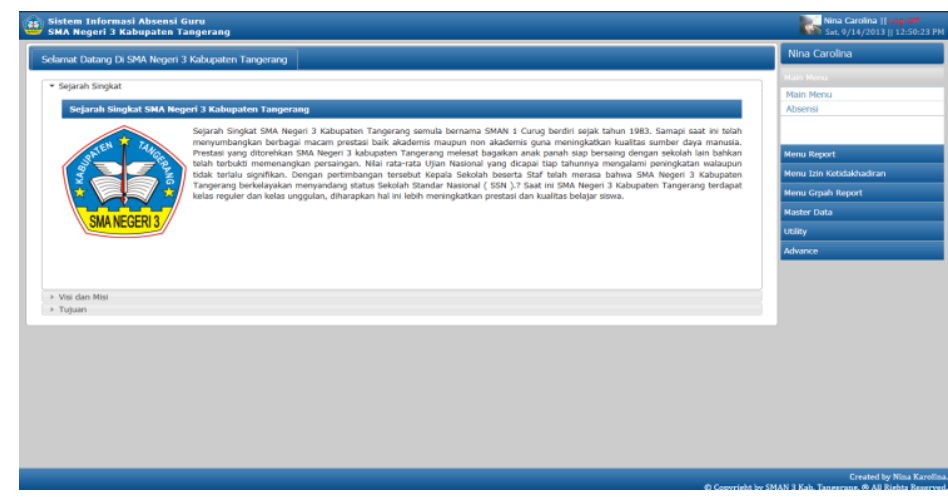

Gambar 4 Tampilan Home

b. Tampilan untuk melakukan absensi guru, sehingga guru hadir dapat melakukan absensi dan langsung ada rekapitulasinya

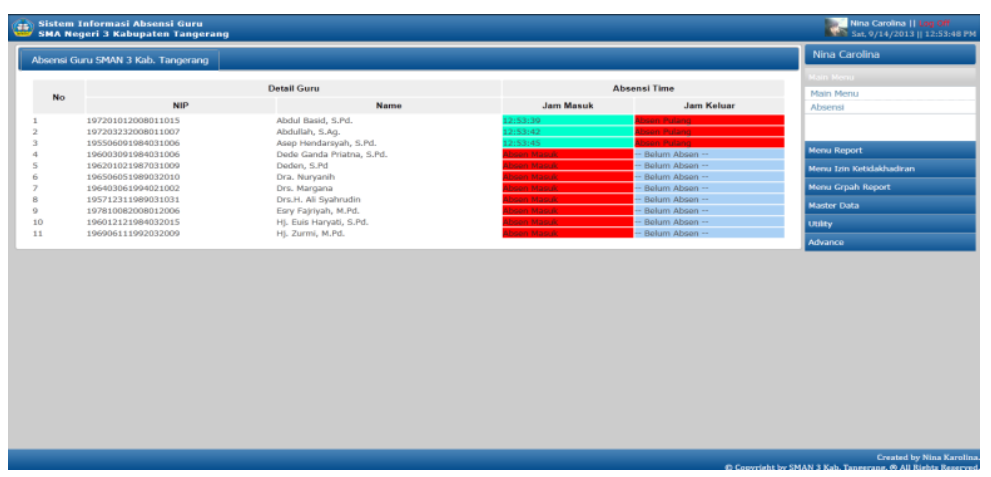

\section{Gambar 5 Tampilan Absensi Guru}

c. Tampilan laporan kehadiran keseluruhan absensi guru

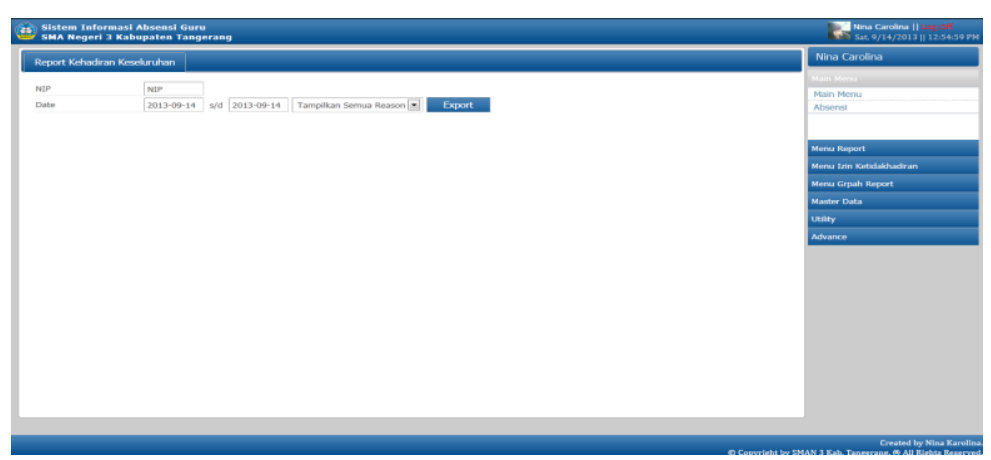

Gambar 6 Tampilan Laporan Kehadiran Guru 
d. Tampilan untuk menampilkan grafik berdasarkan rekapitulasi kehadiran absensi guru dengan sub pilihan menu: hadir, sakit dan ijin

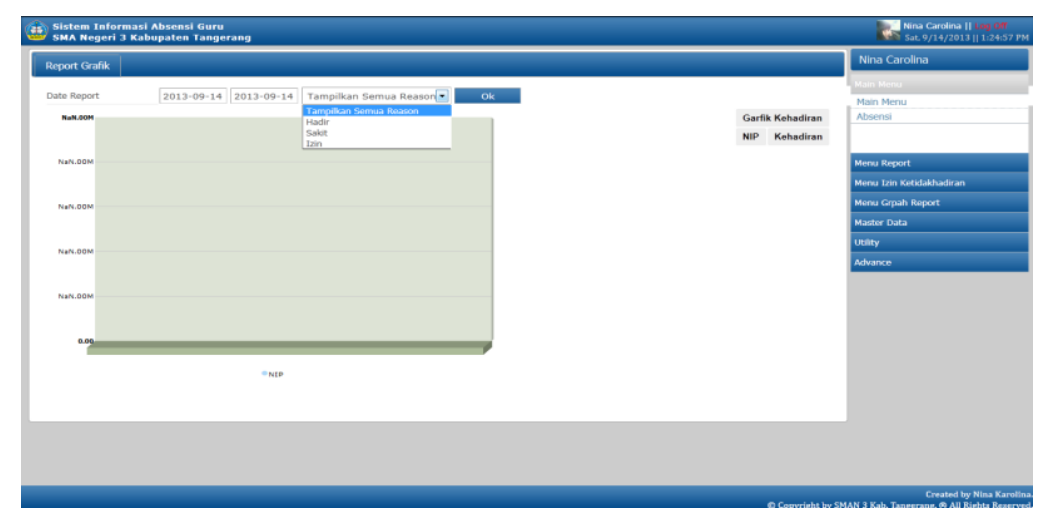

\section{Gambar 7 Tampilan Grafik Berdasarkan Rekapitulasi Kehadiran Absensi Guru Dengan Sub Pilihan}

e. Tampilan grafik absensi kehadiran guru. Hal ini juga dapat bermanfaat untuk mengukur kedisiplinan guru dan kinerja guru karena salah satu aspek terpenting adalah dari sisi kedisiplinan kehadiran.

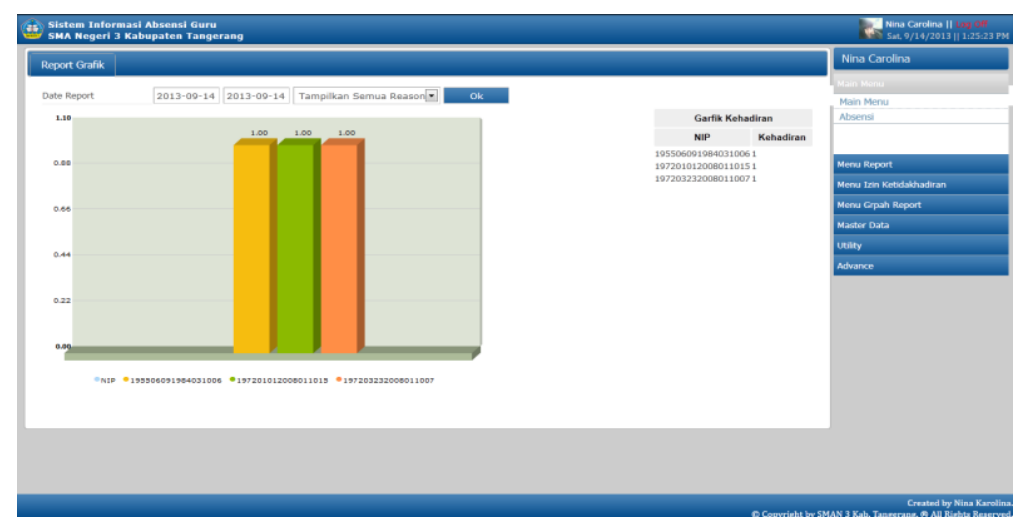

\section{Gambar 8 Tampilan Grafik Grafik Absensi Kehadiran Guru}

\section{KESIMPULAN}

1. Aplikasi absensi ini memerlukan maintenance secara rutin agar aplikasi absensi ini dapat selalu mengikuti perkembangan sistem yang selalu berubah - ubah.

2. Dengan perkembangan teknologi yang sangat cepat, sistem keamanan aplikasi absensi ini juga harus ditingkatkan agar terjaga dengan baik.

3. Diperlukan adanya kerja sama dalam hal ini untuk melakukan kerjasama antara pihak tertentu, sehingga tidak terjadi kesalahan-kesalahan data pada sistem. 


\section{DAFTAR PUSTAKA}

Adi Pranadipa, Sistem Absensi SMAN 4 Batam melalui penerapan Framework Code Igniter, 2013

Andi, Uniform Resource Locator, 2009

Bunafit Nugroho, Structured Query Language, 2010

Fathansyah, Basis dan Data, 2009

Henderi, UML, 2009

Hidayati, Analisa Sistem Biaya Perkuliahan dan Registrasi Mahasiswa pada Perguruan Tinggi Raharja, 2010

Jogiyanto, Analisa dan Desain Sistem Informasi, Pendekatan Terstruktur Teori dan Praktek Aplikasi Bisnis, Ed.2, Cetakan Kedua, Andi Offset, Yogyakarta, 2009

Kristianto Budhi, Hyper Text Markup Language, 2010

Leitel and Davis., Unified Modeling Language”,Raharja Enrichment Centre (REC), Tangerang, 2009

Moch Nurkamarulloh, Analisa sistem informasi Kehadiran Siswa pada SMA Negeri 6 Tangerang 2009

Puji Yurnaningsih, Analisa sistem informasi absensi karyawan pada Perguruan Tinggi Raharja 2010

Sutabri Tata, Analisis \&Disain Sistem Informasi, Pendekatan Terstruktur Teori Dan Praktek Aplikasi Bisnis, AnsiOffseet, Yogyakarta, 2010

wati ismawati, Analisa sistem informasi absensi Pegawai pada Badan Pusat Statistik kota Tangerang, 2009

Ziga Turck, fungsionality dengan stereotypes, 2009 